\title{
Cuprous oxide nanoparticle-inhibited melanoma progress by targeting melanoma stem cells
}

\author{
This article was published in the following Dove Press journal: \\ International Journal of Nanomedicine \\ 5 April 2017 \\ Number of times this article has been viewed
}

\begin{abstract}
Bin Yu, ${ }^{1,2, *}$ Ye Wang, ${ }^{3, *}$ Xinlu Yu, ',* Hongxia Zhang,' Ji Zhu, ${ }^{4}$ Chen Wang,' Fei Chen,' Changcheng Liu,' Jingqiang Wang, ${ }^{2}$ Haiying Zhu'

'Department of Cell Biology, Second Military Medical University, ${ }^{2}$ State Key Laboratory of Genetic Engineering and Collaborative Innovation Center of Genetics and Development, Ministry of Education Key Laboratory of Contemporary Anthropology, Department of Genetics and Development, School of Life Sciences, Fudan University, ${ }^{3}$ Department of Urinary Surgery, ${ }^{4}$ Department of Plastic Surgery, Changhai Hospital, Second Military Medical University, Shanghai, People's Republic of China

*These authors contributed equally to this work
\end{abstract}

Correspondence: Jingqiang Wang State Key Laboratory of Genetic Engineering and Collaborative Innovation Center of Genetics and Development, Ministry of Education Key Laboratory of Contemporary Anthropology, Department of Genetics and Development, School of Life Sciences, Room E20I-7, Life Sciences Building, 2005 Songhu Road, Jiangwan Campus of Fudan University, Shanghai 200438, People's Republic of China Tel +86 2l 51630733

Email jingqiangwang@fudan.edu.cn

Haiying Zhu

Department of Cell Biology, Second Military Medical University, 800,

Xiangyin Rd, Shanghai 200433,

People's Republic of China

Tel +86 2I 81870944

Email hyzhu@smmu.edu.cn

\begin{abstract}
Recent studies have shown that metal and metal oxide have a potential function in antitumor therapy. Our previous studies demonstrated that cuprous oxide nanoparticles (CONPs) not only selectively induce apoptosis of tumor cells in vitro but also inhibit the growth and metastasis of melanoma by targeting mitochondria with little hepatic and renal toxicities in mice. As a further study, our current research revealed that CONPs induced apoptosis of human melanoma stem cells (CD271 ${ }^{\text {+high }}$ cells) in A375 and WM266-4 melanoma cell lines and could significantly suppress the expression of MITF, SOX10 and CD271 involved in the stemness maintenance and tumorigenesis of melanoma stem cells. CD271 $1^{\text {thigh }}$ cells could accumulate more CONPs than CD271-low through clathrin-mediated endocytosis. In addition, lower dosage of CONPs exhibited good anti-melanoma effect by decreasing the cell viability, stemness and tumorigenesis of A375 and WM266-4 cells through reducing the expression of SOX10, MITF, CD271 and genes in MAPK pathway involved in tumor progression. Finally, CONPs obviously suppressed the growth of human melanoma in tumor-bearing nonobese diabetic-severe combined immunodeficiency (NOD-SCID) mice, accompanied with tumors structural necrosis and fibrosis remarkably and decreased expression of CD271, SOX10 and MITF. These results above proved the effectiveness of CONPs in inhibiting melanoma progress through multiple pathways, especially through targeting melanoma stem cells.
\end{abstract}

Keywords: cuprous oxide nanoparticles, CONPs, melanoma, cancer stem cells, A375 cell line, WM266-4 cell line, MITF, SOX10, clathrin-mediated endocytosis

\section{Introduction}

Melanoma is highly aggressive cancer and the most lethal type of skin cancers with high metastatic potential, leaving untreated patients with a median survival of 12 months. ${ }^{1,2}$ Because melanoma has strong resistance to conventional therapies, such as surgical interventions, radiation, and cytotoxic chemotherapies, developing new medicine and therapy tends to be very important in melanoma therapy. ${ }^{3-6}$

Nano medicines have been emerging as one of the new treatment options. ${ }^{7}$ Many nano medicines such as gold nanoparticles, metallic multi-segments, silicon nanowire, iron core-gold shell nanoparticles, chitosan nanoparticles, and gold nanorods have been designed for tumor therapy. ${ }^{8-11}$ As a new member of potential antitumor drugs, cuprous oxide nanoparticles (CONPs) have been proven not only to induce apoptosis of tumor cells selectively in vitro but also to inhibit the growth and metastasis of melanoma by targeting mitochondria with little hepatic and renal toxicities in mice. ${ }^{12,13}$

In the meantime, a lot of studies focusing on the biological properties of melanoma provided more strategies for finding or designing new drugs and therapies. ${ }^{14}$ It is well known that cancer stem cells (CSCs) are considered to be the cause of tumor initiation, metastasis and recurrence and be responsible for the failure of chemotherapy and radiotherapy. Therefore, isolation and identification of CSCs is crucial for facilitating 
monitor, therapy or prevention of cancer. ${ }^{15-18}$ In recent research, lots of biomarkers including ABCB5 (ATP-binding cassette), ${ }^{19,20}$ NGFR (nerve growth factor receptor, CD271) ${ }^{21}$ and ALDH (aldehyde dehydrogenase) ${ }^{22}$ were used to identify melanoma stem cells. However, it should be noted that CD271-positive cells were proven to be "genuine cancer stem cells" by Boiko et $\mathrm{al}^{21}$ and Civenni. ${ }^{23}$ After that, there were a lot of studies supporting that the CD271 positive cells could drive melanoma initiation, progression, immune evasion and drug resistance. ${ }^{21,23-27}$

After we confirmed the effectiveness of CONPs in inhibiting proliferation, tumorigenesis and metastasis of B16F10 in tumor-bearing model, the question we had to answer is whether CONPs could inhibit or kill human melanoma stem cells and whether CONPs have potential to be developed to a novel medicine. In current research, we used two kinds of human melanoma cell lines containing high percentage of CD271 $1^{\text {+high }}$ cells to access the anti-melanoma effectiveness of CONPs in vitro and in vivo, explain why CONPs could target melanoma stem cells with much more superiority in suppressing stemness of melanoma cells and induce the apoptosis of melanoma stem cells. In this study, we gave more supportive evidences on the potential that CONPs could be a new type of drug to cure melanoma in clinic.

\section{Materials and method CONPs synthesis}

CONPs were synthesized according to the previous method. ${ }^{12,13}$ Briefly, adding $0.35 \mathrm{~mL}$ of $0.1 \mathrm{M} \mathrm{CuSO}_{4}$ to $3 \mathrm{~mL}$ of $0.1 \mathrm{M}$ cetyltrimethylammonium bromide in a test tube and allowing the solutions to mix for $\sim 5$ minutes. Then, adding $10 \mathrm{~mL}$ of fresh, chilled $0.04 \mathrm{M} \mathrm{NaBH}_{4}$ to the mixture. The mixture was stirred at $26^{\circ} \mathrm{C}-28^{\circ} \mathrm{C}$ and turned into yellow suspension after $\sim 18$ hours. After being centrifuged at $12,000 \times g$ for 15-20 minutes, the precipitation containing CONPs from the yellow suspension was washed several times with ethanol and deionized water. The final products, CONPs, were dried in a vacuum dryer for $12-18$ hours at $50^{\circ} \mathrm{C}$ and then stored in a hermetic container at $4^{\circ} \mathrm{C}$. All of the chemical reagents used in this experiment were of analytical grade.

\section{Cell culture and mice}

Human melanoma A375 and WM266-4 cell lines were originally obtained from Shanghai Institute of Cell Bank, Chinese Academy of Sciences (Shanghai, People's Republic of China). WM266-4 cells were cultured in Eagle's Minimal Essential Medium (EMEM) (Hyclone, Logan, UT, USA), and A375 cells were cultured in Dulbecco's Modified Eagle Medium (DMEM) medium (Hyclone), supplemented with $100 \mathrm{U} / \mathrm{mL}$ penicillin and $10 \%(\mathrm{v} / \mathrm{v})$ heat-inactivated fetal bovine serum (FBS) in $5 \% \mathrm{CO}_{2}, 95 \%$ humidity incubator at $37^{\circ} \mathrm{C}$.

"Survival A375 cells" and "Survival WM266-4 cells" referred to the adherent cells after A375 and WM266-4 cells were treated with low-dosage CONPs for 72 hours. These cells were washed with phosphate-buffered saline (PBS) and then cultivated in medium without CONPs.

This study was approved by the Institutional Animal Care and Use Committee of Second Military Medical University (SMMU). All the nonobese diabetic/severe combined immunodeficiency (NOD/SCID) mice were purchased from Shanghai Research Center for Model Organisms and raised in specific pathogen-free (SPF) animal rooms of Department of Cell Biology, SMMU. The animals' welfare was guaranteed according to the Institutional Guidelines for the Care and Use of Laboratory Animals in Second Military Medical University and conformed to the National Institutes of Health Guide for Care and Use of Laboratory Animals (People's Republic of China).

\section{Cell proliferation and cell viability assay}

A cell count kit-8 (CCK-8; Dojindo, Mashikimachi, Japan) was used to examine cell proliferation and viability to validate the cytotoxicity of CONPs. A375 and WM266-4 cells were collected and seeded into 96-well dishes for 1,000 cells per well. Cells were cultivated for total 5 days and performed cell viability test by CCK-8 each day. Following the manufacturer's instructions, on day 0 and days $1-5$, previous medium was removed and $100 \mu \mathrm{L}$ DMEM containing $10 \mu \mathrm{L}$ CCK-8 (10\%) was added to each well. After 2-hour incubation at $37^{\circ} \mathrm{C}$, the absorbance at $450 \mathrm{~nm}$ of each well was measured using a Microtiter Plate Reader (TECAN, Männedorf, Switzerland). The average absorbance of 5 independent wells for each group was obtained. The proliferating rate everyday was presented by the ratio of absorbance value of days $1-5$ to value of day 0 .

\section{Apoptosis by annexin V/PI staining}

After A375 and WM266-4 cells in exponential phase were seeded and incubated with CONP medium (1.75, 3.5 and $5.0 \mu \mathrm{g} / \mathrm{mL}$ ) in 6-well culture clusters for 48 hours. Apoptotic and necrotic cells were analyzed by double staining with Alexa Fluor 488-Annexin V and PI (BD, Franklin Lakes, NJ, USA) following the manufacturer's instructions. A total of $5 \mu \mathrm{L}$ Alexa Fluor 488-Annexin V was added to the cell suspension in the presence of $195 \mu \mathrm{L}$ binding buffer and incubated for 20 minutes at room temperature, and then adding $5 \mu \mathrm{L}$ PI immediately. Cells were analyzed using CyAn ${ }^{\mathrm{TM}}$ Flow Cytometer (Beckman, Los Angeles, CA, USA). The percentage of apoptotic (annexin V/PI) and necrotic (annexin V/PI) cells was 
determined by software analysis. Data represented the mean fluorescence obtained from a population of 10,000 cells.

\section{Cell cycle}

A375 and WM266-4 cells were seeded in 6-well culture dishes and incubated in CONP medium $(1.75,3.5$ and $5.0 \mu \mathrm{g} / \mathrm{mL}$ ) for 48 hours. After that, cells were collected and suspended in $70 \%$ ethyl alcohol for 6 hours at $4^{\circ} \mathrm{C}$. Then cells were washed with PBS for 2 times and transferred into special fluorescence-activated cell sorting (FACS) tubes. Cells were stained with cell cycle test kit (BD) for 20 minutes and then tested by CyAn Flow Cytometer (Beckman). The ratios of G1/G0, G2 and S in cell cycle were analyzed by "ModFit LT" software.

\section{Chemical inhibitors}

Five kinds of inhibitors were used in the assay. EIPA (5-[Nethyl- $N$-isopropyl] amiloride) was regarded as the inhibitor of macropinocytosis/phygocytosis while chlorpromazine was the inhibitor of clathrin-mediated endocytosis. Wortmannin could depress not only macropinocytosis but also clathrin-mediated endocytosis indirectly through inhibiting phosphatidylinositol 3-kinase (PI3K) which was one of their common upstream proteins regulating the proteins involved in the endocytosis. The forth inhibitor, $\mathrm{M} \beta \mathrm{CD}$, was an inhibitor of caveola-mediated endocytosis pathway. The last one, dynasore, a cell-permeable, noncompetitive dynamin GTPase activity inhibitor, was used to identify whether dynamin contributed to endocytosis. Each inhibitor was used at safe dosage which should not lead to significant decrease of cell viability as CCK8 assay exhibited.

A375 cells grown in 24-well plates were pretreated with the indicated dosage of chlorpromazine, dynasore, methyl$\beta$-cyclodextrin M $\beta C D$, wortmannin and EIPA (all purchased from Sigma, St Louis, MO, USA) for 2 hours at $37^{\circ} \mathrm{C}$. After the pretreatment, cells were washed with PBS twice and then exposed to CONP medium $(3.5 \mu \mathrm{g} / \mathrm{mL})$. Cells in control group were incubated in CONP medium without pretreatment of inhibitors. Cell viability was determined by the CCK 8 assay. Ratio of CONP group viability to control group viability was used to validate the effect of individual inhibitor.

\section{Tumorigenicity in vivo}

One thousand CD271 thigh and $\mathrm{CD} 271^{- \text {llow }}$ cells obtained by FACS (BD Influx; BD) were harvested in $100 \mu \mathrm{L}$ PBS with $30 \%$ matrigel and then subcutaneously into the inguens of NOD/SCID mice (6 mice per group). Check tumor formation every 2 days. NOD/SCID mice were sacrificed 4 weeks after the injection. Besides, $5 \times 10^{4}$ A375 or survival A375 cells were collected and suspended in $100 \mu \mathrm{L}$ PBS and injected subcutaneously into the inguens of NOD/SCID mice (6 mice per group). NOD/SCID mice were sacrificed 4 weeks after the injection. Tumors were harvested and weighed. The results were shown as the average weights of tumors.

\section{In vivo antitumor property of CONPs}

A375 cells in exponential phase were collected and suspended at $2 \times 10^{6} \mathrm{cells} / \mathrm{mL}$ in PBS (without matrigel) before injection. Seven- to 8-week-old NOD/SCID mice were sedated with tribromoethanol (Sigma) and $100 \mu \mathrm{L}$ cell suspension (containing $10^{5}$ cells) was injected into subcutaneous of mice. Fourteen days later, 12 mice with diameter 5-7 mm tumor were randomly divided into two groups. The mice in CONP treatment group were injected intratumorally with CONPs $-5 \%$ glucose solution at a dose of $16 \mathrm{mg} / \mathrm{kg}$ each day, whereas the control group mice were injected with $5 \%$ glucose solution at the same volume. CONPs were suspended in a $5 \%$ glucose solution using an ultrasonic mixer before injection. The time span for the treatment was 22 days. After that, mice were sacrificed and tumors were subjected to hematoxylin and eosin (H\&E) stain, Sirius stain and immunohistochemistry assay after being weighed and fixed in 4\% paraformaldehyde solution.

\section{Western blotting}

Cells were solubilized for 10 minutes in protein buffer (Beyotime). The primary antibody was incubated for 10 hours at $4^{\circ} \mathrm{C}$. After 3 washes of 10 minutes in TBST containing $1 \%$ Triton $\mathrm{X}-100$, the secondary antibody coupled with horse radish peroxidase was then incubated for 40 minutes at $37^{\circ} \mathrm{C}$. After three additional washes, proteins of interest were revealed by ECL (Amersham, Uppsala, Sweden). Antibodies used were MITF (Cell Signaling Technology), BCL-2 (Cell Signaling Technology), SOX10 (Cell Signaling Technology), CD271 (R\&D), GAPDH (Cell Signaling Technology), p-BRAF (Cell Signaling Technology) and p-ERK (Cell Signaling Technology). The bound antibody was detected with peroxidase-conjugated anti-rabbit secondary antibody or anti-mouse secondary antibody followed by chemiluminescence.

\section{Immunohistochemistry}

Tumors were made into tumor arrays through paraffin embedding and paraffin sectioning. After dewax and rehydrate, tumor arrays were stained with MITF (R\&D), SOX10 (R\&D), CD271 (R\&D) and Ki-67 (R\&D) for 6-8 hours. Phosphate buffered saline and $0.5 \%$ Tween 20 were used to wash samples for 3 times, 5 minutes for each time. The bound antibody was detected with NorthernLights ${ }^{\mathrm{TM}}$ Antibody. Pictures were taken by fluorescence microscopy. 


\section{Sphere forming assay}

After treated with CONPs $(1.75 \mu \mathrm{g} / \mathrm{mL})$ for 72 hours, 2000 A375 or WM266-4 cells were seeded into low-adhesion 6-well plates (Corning) and cultivated in DMEM or EMEM with $2 \mathrm{ng} / \mathrm{mL}$ Epidermal Growth Factor (EGF) (Sigma), and $2 \mathrm{ng} / \mathrm{mL}$ basic Fibroblast Growth Factor (bFGF) (Sigma). After 5-day incubation, 5 random images of each well were taken. The number of sphere (diameter $\geq 50 \mu \mathrm{m}$ ) and single cell were counted separately under microscopic and the average value of 5 images were taken respectively. The ratio of sphere number to single cell number presented the sphere formation efficiency (SFE).

\section{Invasion assay}

A total of $100 \mu \mathrm{L}$ diluted matrigel was put into upper chamber of 24-well transwell and the transwells were incubated at $37^{\circ} \mathrm{C}$ at least $4-5$ hours for gelling. CONP-treated cells and control cells were harvested and washed with EMEM or DMEM without FBS. Then gently wash gelled matrigel with prewarmed serum-free culture media before seeding $100 \mu \mathrm{L}$ of cell suspension $\left(10^{6} / \mathrm{mL}\right)$ onto the matrigel. Lower chamber of the transwell was filled with $600 \mu \mathrm{L}$ of culture media as an adhesive substrate. After 20- to 24-hour incubation, scrape off the cells on the top of the transwell with a cotton swab and stained with crystal violet solution. The number of invasive cells were counted under a light microscope.

\section{Intracellular $\mathrm{Cu}$ evaluation and graphite} furnace atomic absorption spectrometry Intracellular $\mathrm{Cu}$ means the total amount of copper in cells. After pretreated with or without inhibitor and exposed to CONPs, cells were collected and digested with concentrated nitric acid (guaranteed reagent 65\%; Merck, Darmstadt, Germany) for 10 hours at $4^{\circ} \mathrm{C}$ and cells were cracked. Then, samples were heated at $150^{\circ} \mathrm{C}$ for cleaning out the acid thoroughly. Diluted with $25 \mathrm{~mL} \mathrm{H}_{2} \mathrm{O}$, the final copper mass for each sample was analyzed by Graphite Furnace Atomizer (AA240Z; Agilent, Santa Clara, CA, USA). Every sample was measured 3 times. The mass of intercellular $\mathrm{Cu}(\mu \mathrm{g})$ per $10^{7}$ cells represented the final content in cells. The cell number could be calculated with hemocytometer or FACS before acid treatment.

\section{Statistical analysis}

Data represented the results for assays performed in triplicate, with error bars to represent standard deviation or standard error of the mean. Statistics used were as follows: predominately Student's $t$-test and one-way analysis of variance with Tukey's post hoc test performed using GraphPad Prism version 6.00 for Mac OS, GraphPad software. Pearson's correlation was used to analyze associated gene expression and Wilcoxon-Mann-Whitney test to analyze tumor growth. Throughout the text, $P<0.05$ and $P<0.01$.

\section{Result and discussion CONP induced apoptosis of melanoma stem cells in A375 and WM266-4 melanoma cell lines in vitro}

In order to make clear that whether $\mathrm{CD} 271^{\text {+/high }}$ cells existed in human melanoma cell lines, we used Flow Cytometry (FCM) to test the ratio of $\mathrm{CD} 271^{\text {+high }}$ cells in melanoma cell lines. As the results showed, the ratio of CD271 ${ }^{\text {thigh }}$ in A375 and WM266-4 cell lines were $30 \%$ and $45 \%$, respectively (Figure 1A).
A
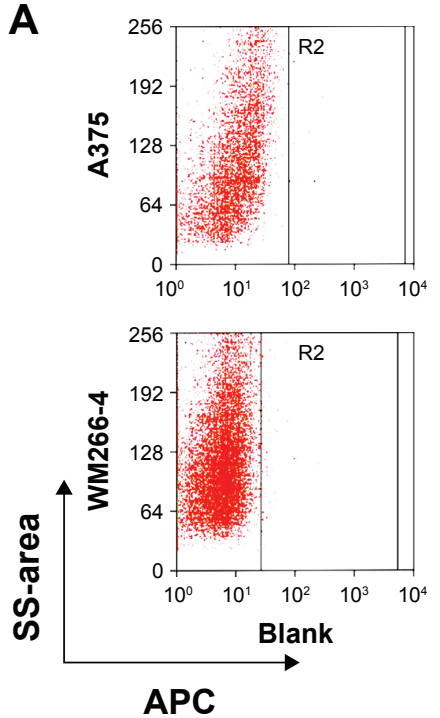
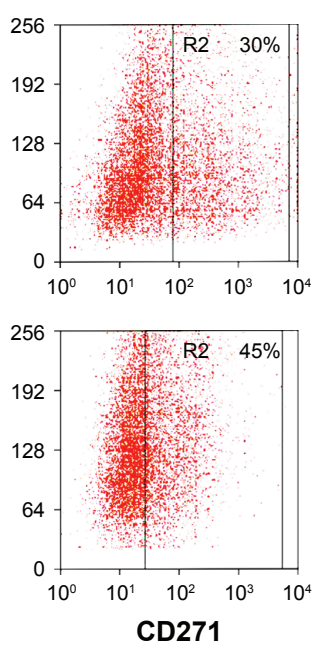

B

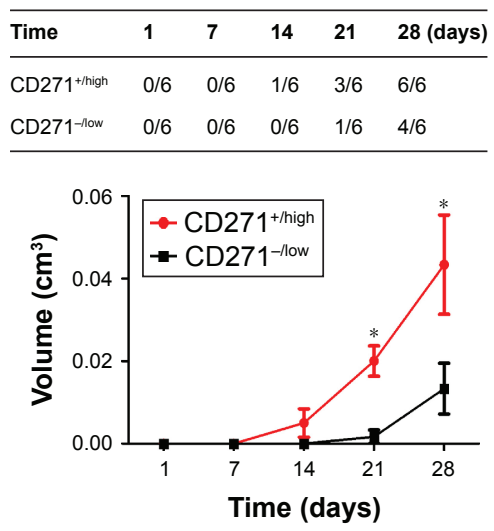

Figure I (Continued) 
C
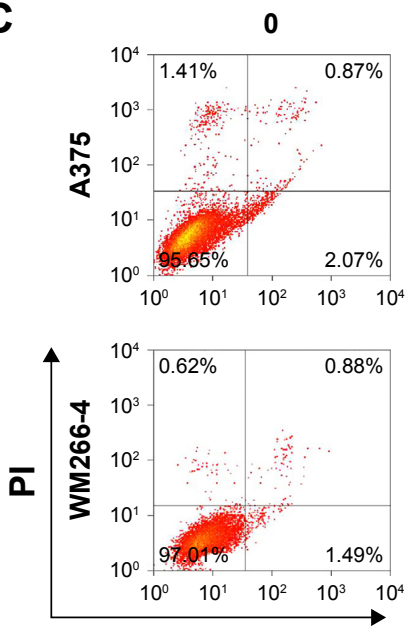

Annexin V-FITC

E
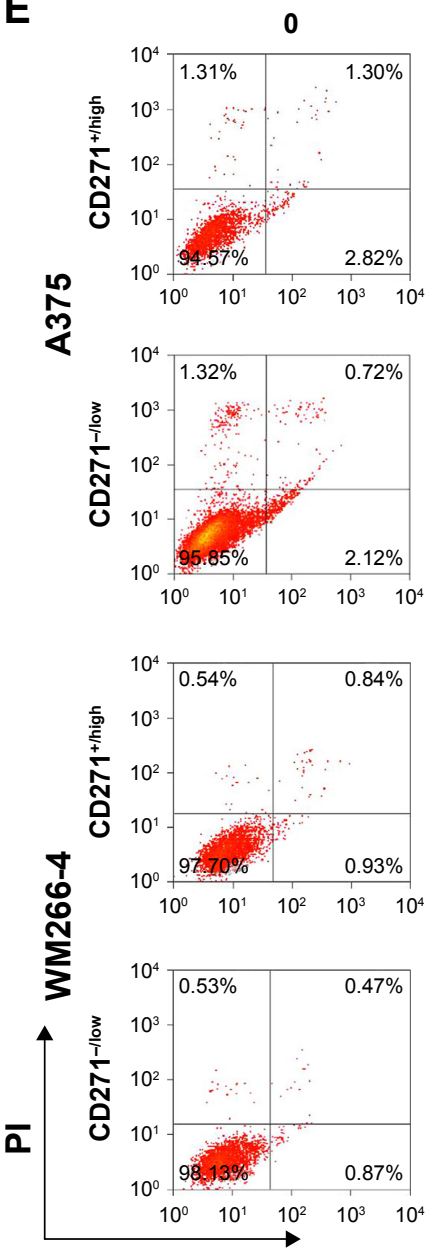

Annexin V-FITC
1.75
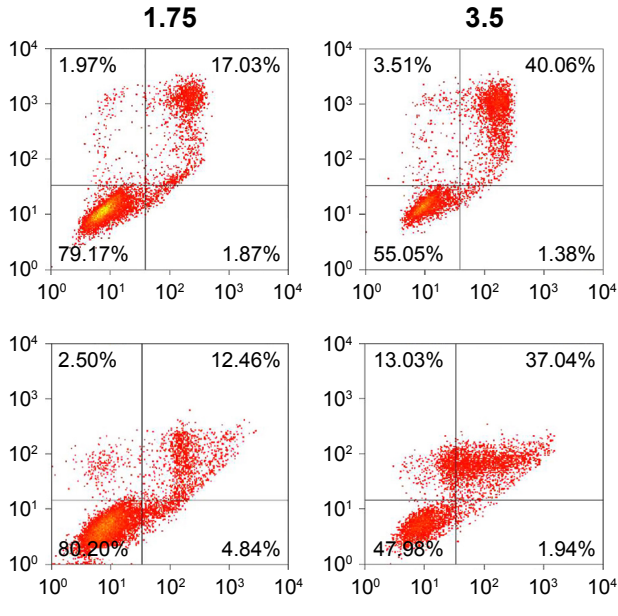
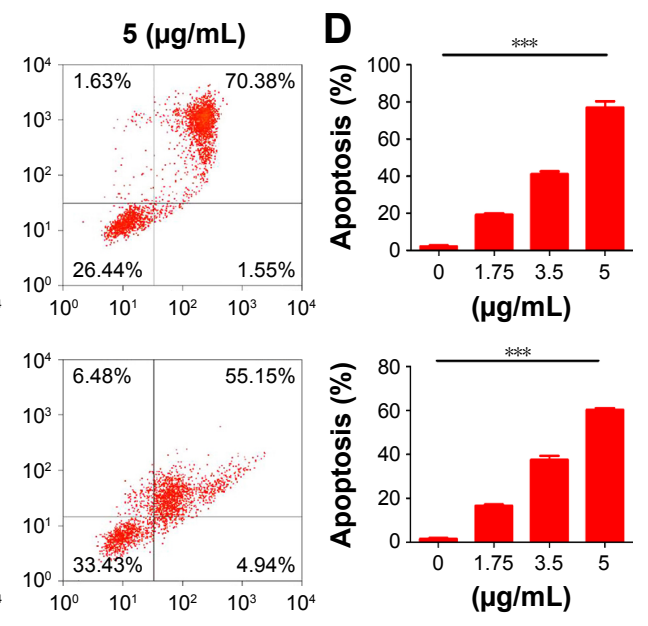

igure I CONP induced apoptosis of melanoma stem cells in A375 and WM266-4 melanoma cell lines in vitro.

Notes: (A) Representative flow cytometry graphs illustrated that the ratio of CD27I positive cells in A375 was $30 \%$ and in WM266-4 cells was $45 \%$. (B) In vivo tumorigenicity of $\mathrm{CD} 27 \mathrm{I}^{\text {thigh }}$ and $\mathrm{CD} 27 \mathrm{I}^{- \text {-low }}$ cells in $\mathrm{A} 375$ cells determined by subcutaneous injection in NOD/SCID mice with $10^{3}$ cells, respectively. The growth rate of CD27/ thigh cell tumors was lower than that of CD271-1low cell tumors in NOD/SCID mice. Six mice per group. (C,D) Representative flow cytometry dot plots and graphs of apoptosis and necrosis showed the ratio of apoptosis and necrosis cells in A375 and WM266-4 cells incubated in CONP medium for 48 hours significantly increased in dosage-dependent manner, $n=3$. (E,F) Representative flow cytometry dot plots and graphs of apoptosis and necrosis of CD27/ thigh and CD271-llow cells in A375 and WM266-4 cells showed similar apoptosis and necrosis ratio of CD271+high as CD271-low cells after A375 and WM266-4 cells were incubated in CONP medium for 48 hours. Representative images were showed, $\mathrm{n}=3$. The error bars represent \pm standard deviation $(* P<0.05, * * * P<0.001) ; n=$ biological replicates.

Abbreviations: CONPs, cuprous oxide nanoparticles; NOD-SCID, nonobese diabetic-severe combined immunodeficiency. 
Furthermore, we sorted the CD271 $1^{\text {thigh }}$ cells and CD271-llow from A375 cells by FACS and compared the tumorigenesis of CD271 $1^{\text {thigh }}$ cells with $\mathrm{CD} 271^{- \text {llow }}$ in NOD/SCID mice. As shown in Figure 1B, when $1000 \mathrm{CD} 271^{\text {thigh }}$ cells with matrigel $(30 \%)$ were injected into inguen of NOD/SCID mice subcutaneously, we could observe the formation of tumors as early as at 14 days, whereas $1000 \mathrm{CD} 271^{\text {-low }}$ cells tumors formed at the 21 days and the average volume of tumors were significantly smaller than CD271 ${ }^{\text {thigh }}$ tumors. As we expected, CONPs could induce apoptosis of A375 and WM266-4 melanoma cells in the dose-dependent manner as shown in Figure 1C and D. In order to make certain whether CONPs could induce the apoptosis of melanoma stem cell in A375 cells, we further analyzed the apoptosis of CD271 $1^{\text {thigh }}$ cells and CD271-low cells separately. As presented in Figure 1E and $\mathrm{F}$, the apoptosis ratio of $\mathrm{CD} 271^{\text {thigh }}$ was similar as $\mathrm{CD} 271^{- \text {-low }}$ cells with dose-dependent manner. These results suggested that melanoma stem cells might not escape from apoptosis induced by CONPs.
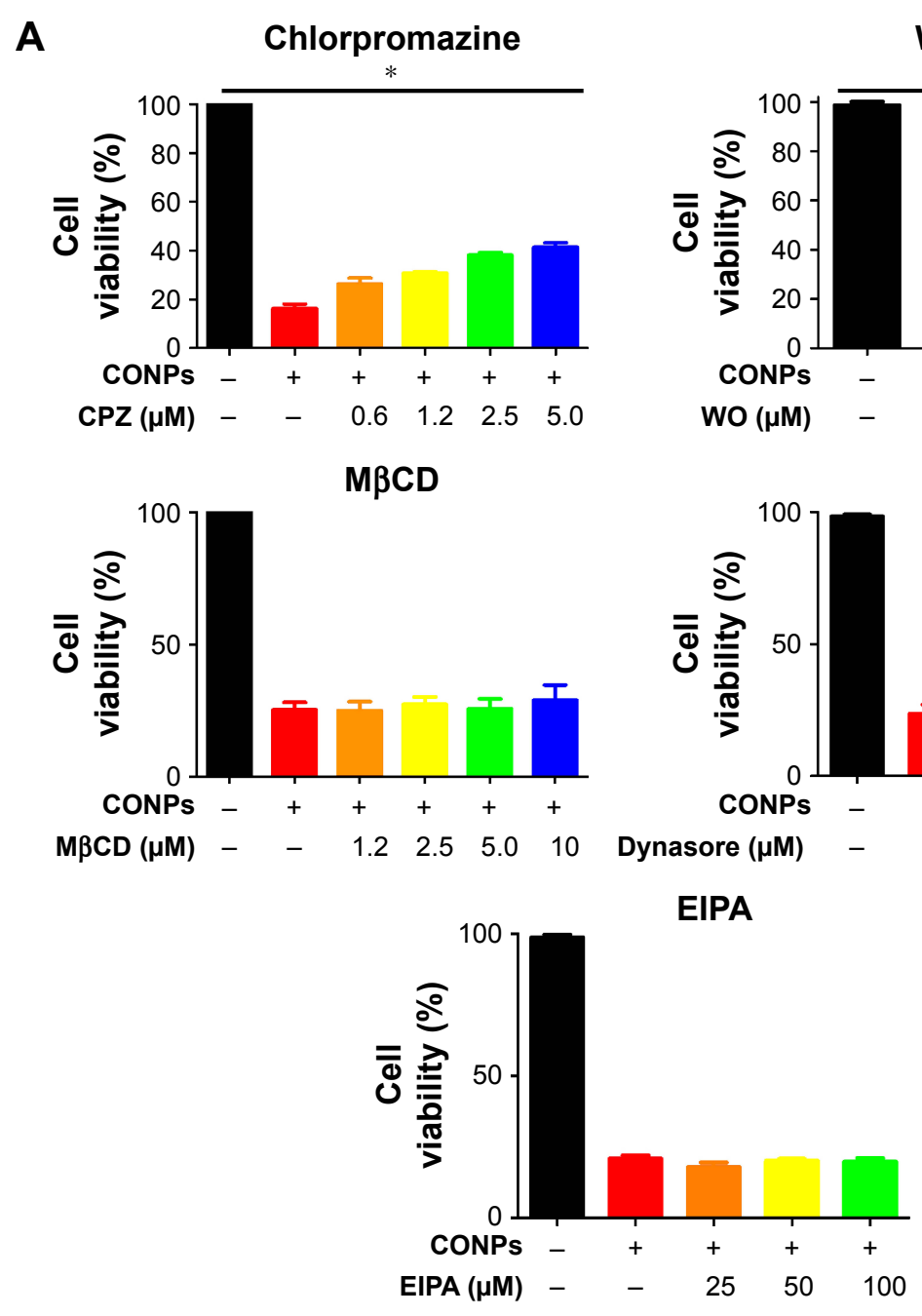

CD27 I thigh melanoma cells could take in more CONPs than CD27I-llow through clathrin-mediated endocytosis

Nanoparticles usually tend to enter into cells by endocytosis. In order to elucidate the antitumor mechanism of CONPs, it is necessary to investigate the way through which CONPs enter into cells. We used 5 kinds of inhibitors to detect the mechanism about the internalization of CONPs. As we know, EIPA is regarded as the inhibitor of macropinocytosis/phygocytosis, while chlorpromazine is the inhibitor of clathrin-mediated endocytosis. $\mathrm{M} \beta \mathrm{CD}$ could inhibit caveola-mediated endocytosis. After making certain the safe dosage of each inhibitor, we treated cells with 2-hour inhibitor/48-hour CONPs and observed the improvement of cell viability resulting from the protection of safe dosage inhibitors. As shown in Figure 2A, chlorpromazine could improve the cell viability in dose-dependent manner from $18 \%$ to $40 \%$ whereas EIPA and M $\beta C D$ hardly increased the ratio. The result indicated that the internization
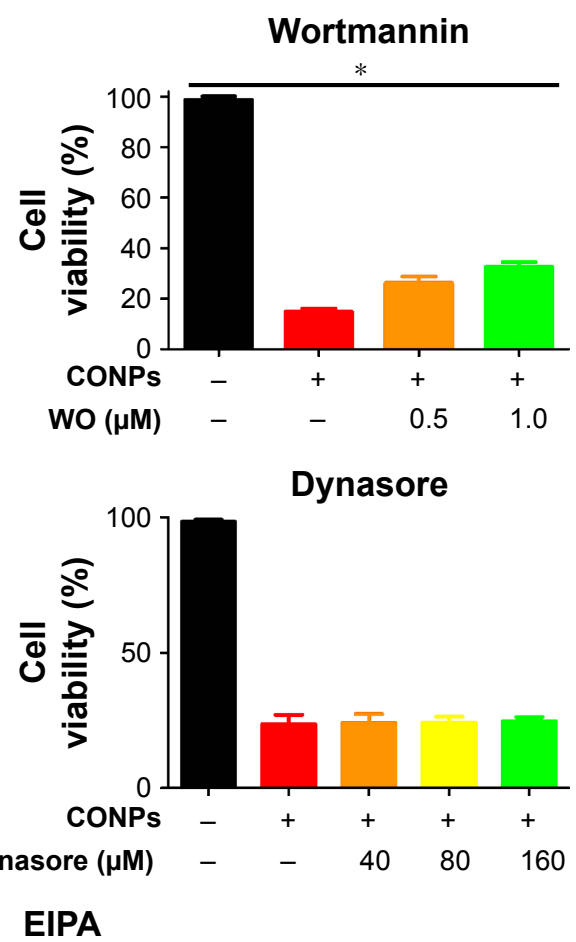

Figure 2 (Continued) 

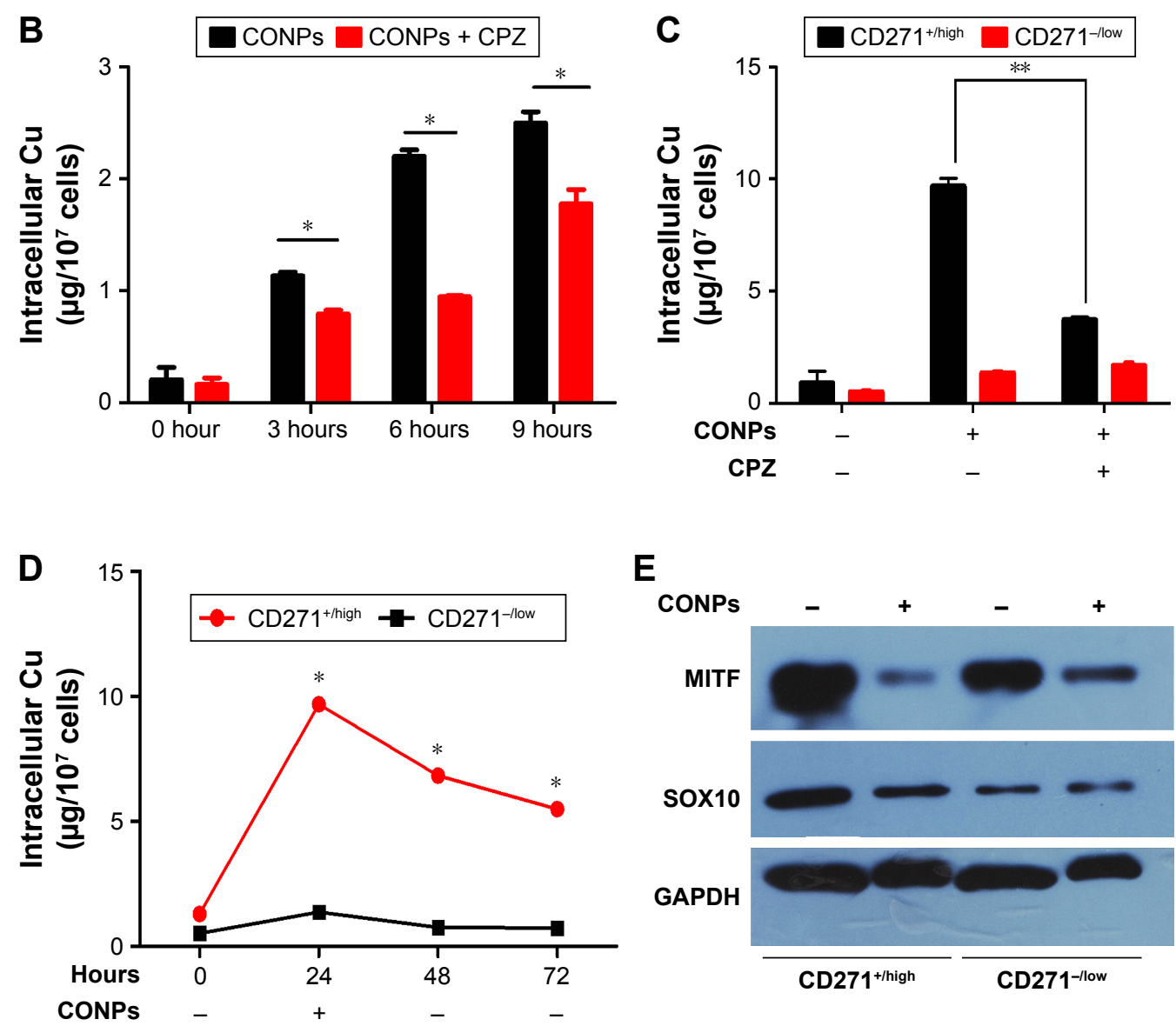

Figure 2 The CD27I $I^{\text {thigh }}$ melanoma cells could take in more CONPs than CD27I Illow through clathrin-mediated endocytosis.

Notes: (A) Wortmannin and chlorpromazine rather than dynasore, M $\beta C D$ and EIPA could promote cell viability. Specific endocytosis inhibitors increased the cell viability of A375 cells treated by CONPs. After being pretreated with 5 kinds of endocytosis inhibitors respectively at different concentrations, A375 cells were cultivated in CONP medium $(3.5 \mu \mathrm{g} / \mathrm{mL})$ for 48 hours. Cells in control group were incubated in CONP medium without pretreatment of inhibitors. CCK8 assay was used to validate effect of inhibitor, $n=3$. (B) Chlorpromazine $(5 \mu \mathrm{M})$ declined the content of $\mathrm{Cu}$ of $\mathrm{A} 375$ cells through inhibiting absorption of $\mathrm{A} 375$ cells. A375 cells were incubated in CONP medium $(3.5 \mu \mathrm{g} / \mathrm{mL})$ for 3,6 and 9 hours after chlorpromazine treatment for 2 hours. Intracellular Cu means the total content of Cu in $10^{7}$ A375 cells, $n=3$. (C) Chlorpromazine $(5 \mu \mathrm{M})$ could significantly decline the content of $\mathrm{Cu}$ in CD27I ${ }^{\text {thigh }}$ cells. After treating A375 as (B), A375 cells were separated into CD27I+/high cells and CD27I-llow cells by FACS and the intracellular Cu was tested by GF-AAS, $\mathrm{n}=3$. (D) After cells were treated with CONPs (3.5 $\mu \mathrm{g} / \mathrm{mL})$ for $24 \mathrm{hours}$, one part of cells was harvested for GF-AAS test, whereas the other part of cells was transferred into CONP-free medium and harvested after 24 and 48 hours, respectively for GF-AAS test. (E) The expression of MITF and SOXI0 decreased in CD27I +high and CD27I-llow cells after CONP treatment. A375 cells were treated with CONPs (I.75 $\mu$ g/mL) for 72 hours, collected and separated into $C D 27 I^{\text {thigh }}$ and $C D 27 I^{- \text {llow }}$ cells by FACS for Western blotting. The error bars represent $\pm s t a n d a r d ~ d e v i a t i o n ~(* P<0.05$, $* * P<0.01$ ); $\mathrm{n}=$ biological replicates.

Abbreviations: CONPs, cuprous oxide nanoparticles; FACS, fluorescence-activated cell sorting; GF-AAS, graphite furnace atomic absorption spectrometry; EIPA, 5-(Nethyl-N-isopropyl) amiloride.

of CONPs in melanoma would depend on clathrin-mediated endocytosis pathway instead of macropinocytosis or caveola-mediated endocytosis pathway. Furthermore, the result about dynasore, a cell-permeable, noncompetitive dynamin GTPase activity inhibitor, suggested that dynamin did not contribute to the endocytosis. Besides, we observed that wortmannin could increase the cell viability by $15 \%$, which could be considered as supportive evidence that CONPs could be taken in by clathrin-mediated endocytosis because wortmannin could depress not only macropinocytosis but also clathrin-mediated endocytosis through inhibiting phosphatidylinositol 3-kinase (PI3K), which is one of their common upstream proteins regulating the activity of proteins involved in the endocytosis. Hence, based on the final protection effectiveness of specific inhibitor, we proposed the clathrin-mediated endocytosis should be the dominant contribution to uptaking CONPs in melanoma cells. Supportively, quantitative analysis by graphite furnace atomic absorption spectrometry (GF-AAS) presented that chlorpromazine significantly reduced $\mathrm{Cu}$ content of A375 cells exposed to CONPs compared with the control cells, which further validating clathrin-mediated endocytosis is the major pathway of CONPs internalization into melanoma cells (Figure 2B).

More interesting, we also found that CD271 $1^{\text {thigh }}$ cells could take in more CONPs than CD271 ${ }^{-/ \text {low }}$ cells did. The GF-AAS data presented that after exposed to CONPs (3.5 $\mu \mathrm{g} / \mathrm{mL})$ for 24 hours, the $\mathrm{Cu}$ content of CD271 $1^{\text {thigh }}$ cells 
is higher than CD271-low cells by 4 times (Figure 2C). After removing CONPs from medium and incubated for another 48 hours, the content of CD $271^{\text {+high }}$ cells decreased by $\sim 30 \%$ whereas CD271-/low did not show significant alteration, which indicated that $\mathrm{CD} 271^{\text {+/high }}$ cells had the competency to expel CONPs or $\mathrm{Cu}$ from cells. Nonetheless, the $\mathrm{Cu}$ content of CD271 $11^{\text {/high }}$ cells was still higher than CD271-/low cells by 2 times after 48 hours (Fig 2C). Furthermore, we investigated that chlorpromazine could decrease the content of $\mathrm{Cu}$ in CD271 $1^{\text {+high }}$ cells but not that in CD271 ${ }^{-/ \text {low }}$ cells (Figure 2D), which suggested clathrin-mediated endocytosis is the main pathway to take in CONPs for melanoma stem cells.

\section{CONPs could significantly suppress the expression of MITF and SOXIO of melanoma stem cell}

Our further research focused on the investigation of gene expression involved in the stemness maintenance and proliferation of melanoma stem cells. First, A375 cells were exposed to CONPs $(1.75 \mu \mathrm{g} / \mathrm{mL})$, and then survival cells were collected and separated into CD271 $1^{\text {thigh }}$ and CD271-/low cells. We testified the dramatic declination of MITF and SOX10 in CD271 $1^{\text {/high }}$ cells in A375 cell line after treatment with lowdosage CONPs $(1.75 \mu \mathrm{g} / \mathrm{mL})$ for 72 hours through Western blot (Figure 2E). Besides, we also found that although the expression of MITF and SOX10 in CD271-low cells and CD271 $1^{\text {thigh }}$ cells appeared to be reduced after exposing to CONPs for 72 hours, the falling range of gene expression in CD271+/high cells is much higher than that of CD271-/low, which was consistent with the result that $\mathrm{CD} 271^{\text {+high }}$ cell could take in more CONPs than CD271-/low cells. Therefore, we proposed that just low-dosage CONPs could produce favorable antitumor effect on melanoma through targeting on $\mathrm{CD} 271^{\text {thigh }}$ cells, reducing the expression of genes involved in the stemness maintenance of melanoma CD271+/high cells.

\section{Low dosage of CONPs suppressed the stemness and tumorigenesis of $A 375$ and WM266-4 cells through reducing the expression of genes involved in tumor progression}

After we found CONPs could decrease the expression of CD271 and SOX10 in vitro, we want to explore whether low-dosage CONPs could reduce stemness of melanoma cells. CCK8 assay exhibited that when A375 and WM266-4 cells were kept in medium containing $1.75 \mu \mathrm{g} / \mathrm{mL}$ CONPs, CONPs successfully inhibited the growth of two kinds of cells during 72 hours. Meanwhile, CONPs could depress the sphere formation of them during 72 hours treatment as shown in Figure 3A and B. However, we also observed that there were $80 \%$ survived cells in both A375 and WM266-4 cells after treated with CONPs for 48 hours as shown in Figure 1D, which inspired us to explore the properties of the remaining survived cells, especially the stemness of these cells. After A375 and WM266-4 were treated with CONPs, the remaining adherent cells, survival cells, were cultivated in CONP-free medium for another 48 hours and then collected. The cell cycle assay showed that G0/G1 arrest of the survived A375 and WM266-4 cells (Figure 3C). Also, CCK8 analysis showed that proliferation of both cell lines decreased by $80 \%$ after cells were incubated in CONP-free medium for 5 days compared with the control group (Figure 3D). And then, we incubated the survived A375 and WM266-4 melanoma cells in sphere-forming medium without CONPs in low-adhesion 6-well dishes for another 5 days and discovered the sphereforming percentage of A375 and WM266-4 cells declined by almost $80 \%$ compared with the melanoma cells in control group (Figure 3E). Moreover, transwell assay presented the even lower invasion of survived A375 cells and WM266-4 cells than the control groups shown in Figure 3F. In addition, as we all know, tumorigenesis of tumor cells is the critical property in identifying CSCs. In current research, after being treated by medium containing $1.75 \mu \mathrm{g} / \mathrm{mL}$ CONPs for 3 days, $5 \times 10^{4}$ A 375 survival cells were collected and injected into inguens of NOD/SCID mice subcutaneously. As expected, the survival A375 cells hardly form tumors in the 4th weeks while control cells could form tumors, which indicated the capacity of tumorigenesis in vivo and stemness of A375 cells treated by low-dosage CONPs had been declined dramatically (Figure 3G).

As reported, the nerve growth factor receptor CD271, the SRY-box transcription factor SOX10, microphthalmiaassociated transcription factor MITF and MPK pathway tended to be important in initiation and progress of melanoma. In the current research, Western blot results exhibited the significant decrease of CD271, SOX10, MITF, p-BRAF and p-ERK under low dosage of CONP treatment in timedependent manner (Figure 3H).

\section{CONPs depressed the growth of melanoma effectively in vivo}

We established tumor-bearing NOD/SCID mouse models with A375 cells and observed the depression of tumors after CONPs were injected into tumors. When the diameter of tumors got to 5-7 mm, CONPs were injected into tumors every 2 days for the total of 22 days with glucose injected in 
the same way as control (Figure 4A). The results showed that compared with the control group, tumors of CONPs group showed much lower in volume and weight (Figure 4B and C). The more important is that H\&E staining revealed the structural damage of tumors in CONPs group while the tumors structure of control group was integrated (Figure 4D). And also, by Sirius red staining, we discovered fibrosis appeared in tumors treated with CONPs for 22 days. In addition, immunohistofluorescence stain revealed that expression of Ki-67 remarkably declined in tumors after exposed to CONPs compared with control tumors (Figure 4E). The above results confirmed that CONPs indeed not only inhibited the growth of tumors effectively by suppressing the expression of cell cycle gene, but also changing the tumor structure,

\section{A}

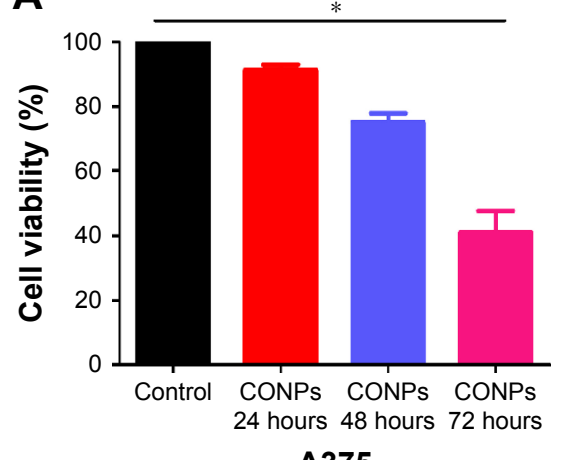

A375

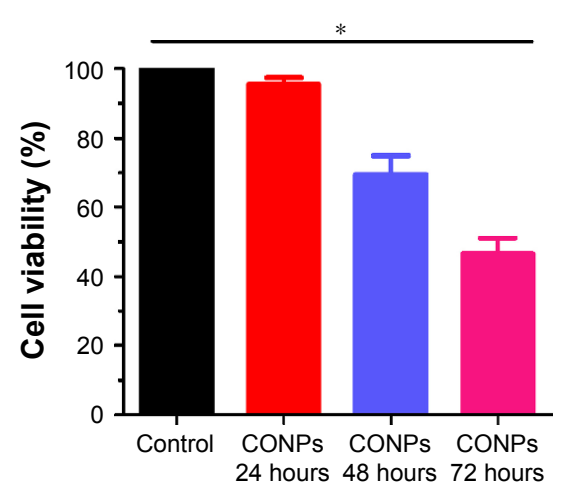

WM266-4
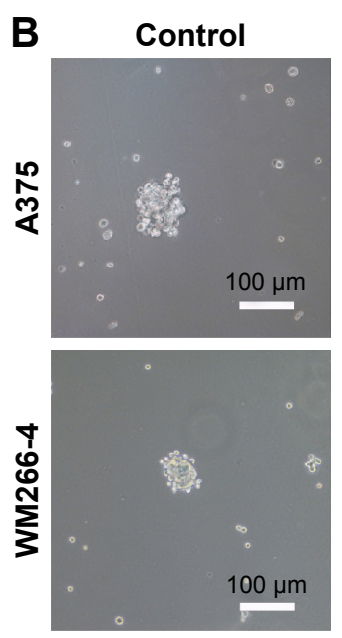

C

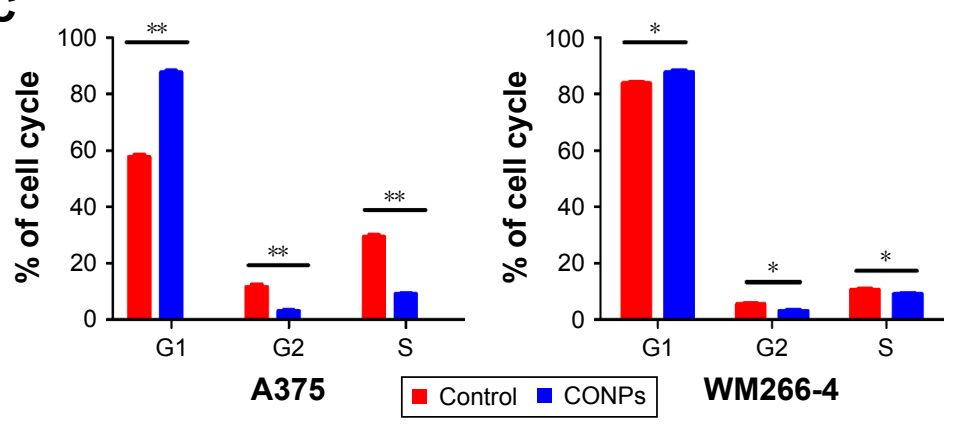

CONPs

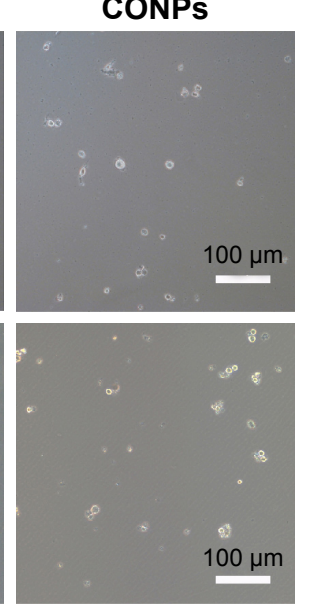

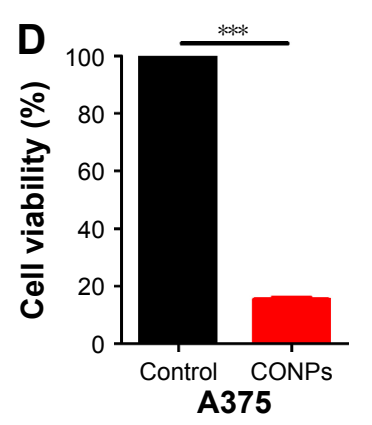

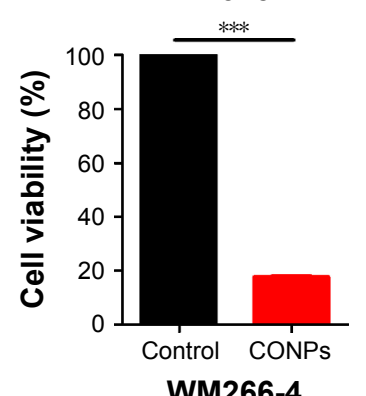

E
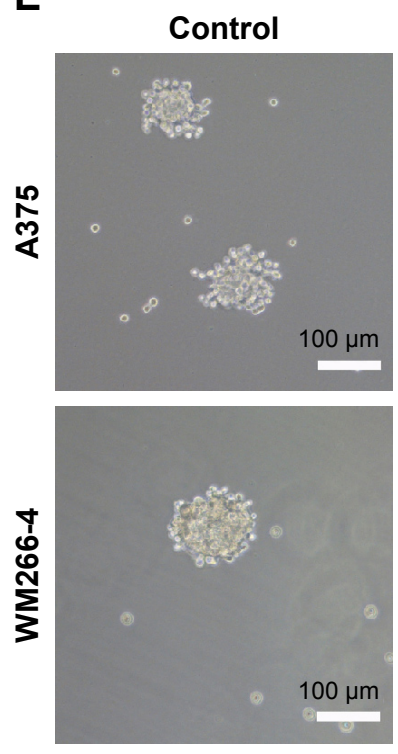
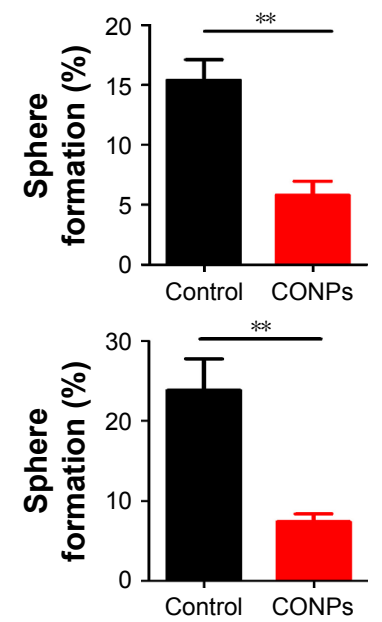

CONPs
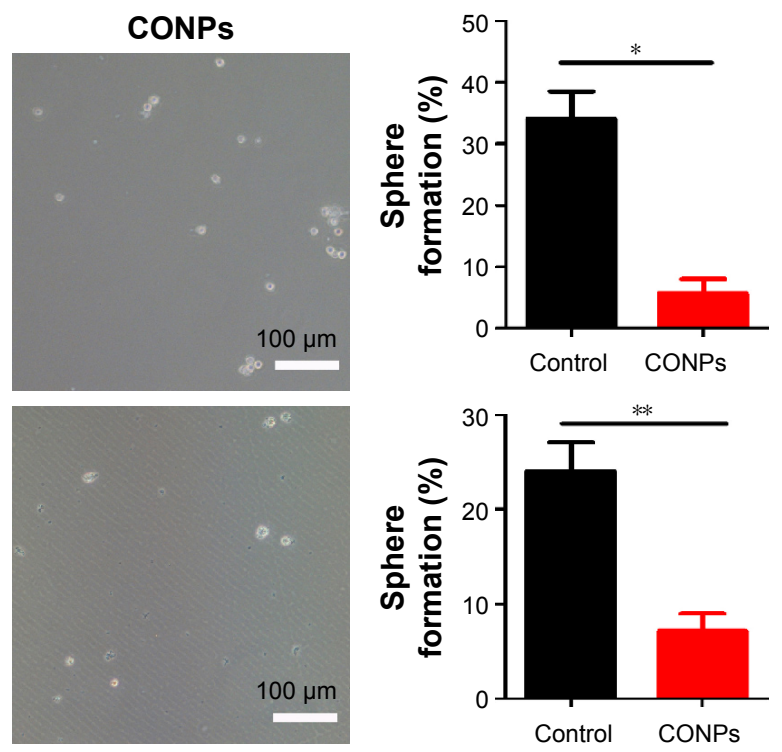

Figure 3 (Continued) 

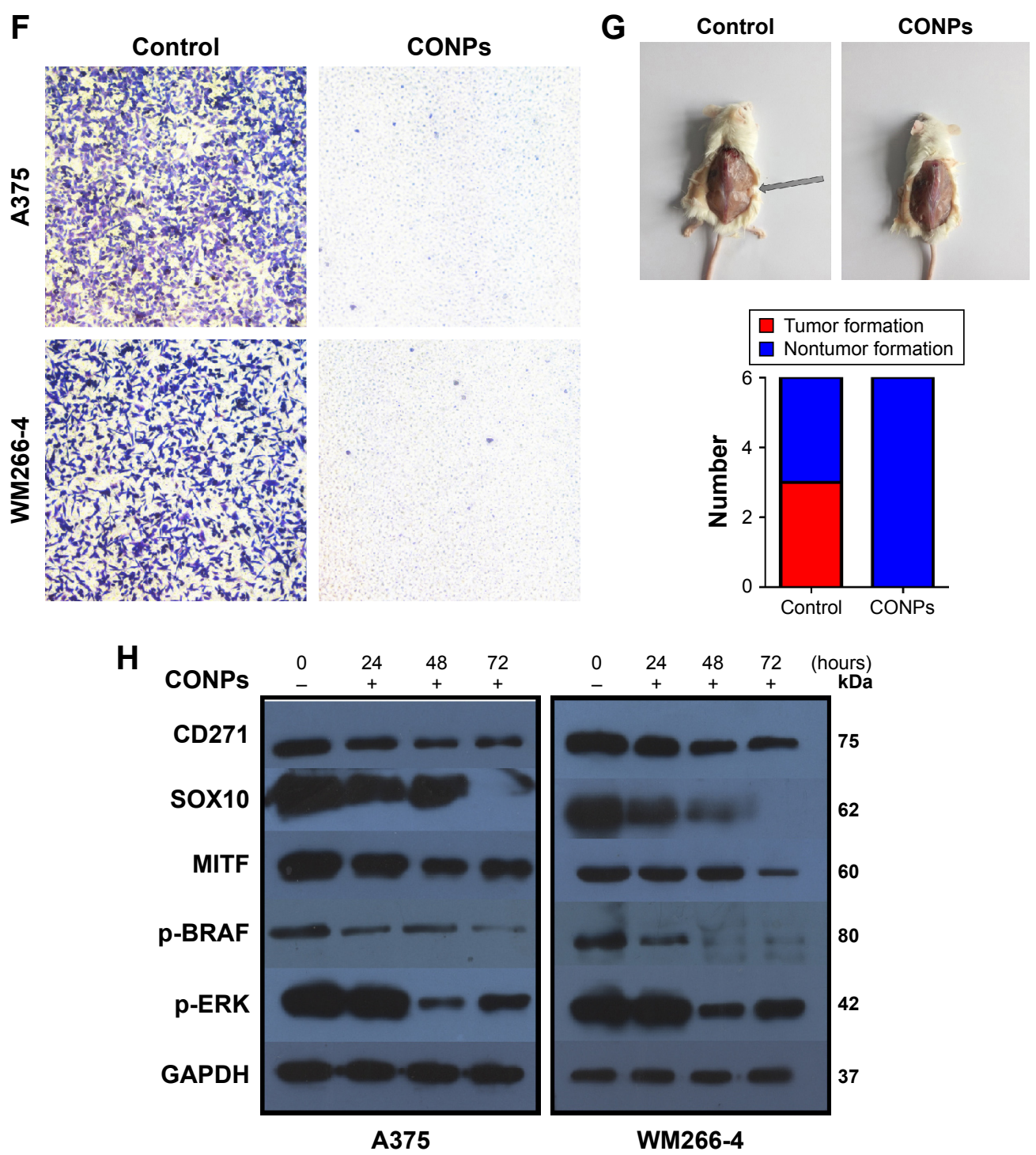

Figure 3 Low dosage of CONPs suppressed the stemness and tumorigenesis of A375 and WM266-4 cells through reducing the expression of genes involved in tumor progression.

Notes: (A) The cell viability of A375 and WM266-4 cells treated with CONPs ( $1.75 \mu \mathrm{g} / \mathrm{mL}$ ) for 24,48 and 72 hours, $\mathrm{n}=3$. (B) SFE of cells which were kept in CONP medium $(1.75 \mu \mathrm{g} / \mathrm{mL})$ for 120 hours reduced significantly compared with the untreated cells. The number of sphere (diameter $\geq 50 \mu \mathrm{m})$ was counted at day 5 . Scale bars represent $100 \mu \mathrm{m}, \mathrm{n}=3$. (C) Cell cycle of survival cells after A375 and WM266-4 cells were exposed to low dosage of CONPs for 72 hours showed G0/GI arrest, $\mathrm{n}=3$. (D) Cell viability of survival cells cultivated in CONP-free medium for 120 hours was lower than normal cells, $n=3$. (E) Representative images of sphere deriving from survival A375 to WM266-4 cells cultivated for 120 hours. Data showed that the SFE of survival cells decreased comparing with normal cells. Scale bars represent $100 \mu$ m, $n=3$. (F) Representative images of transwell analysis of survival A375 and WM266-4 cells showed declined invasion of survival cells, n=3. (G) Tumorigenesis of survival A375 cells in NOD/SCID mice reduced comparing with control cells. A total of $5 \times 10^{4}$ cells were injected subcutaneously and observed for 28 days. Six mice per group. (H) Western blot results exhibited the significant decrease of CD27I, SOXI0, MITF, p-BRAF and p-ERK expression in time-dependent manner after low dosage of CONPs treatment. The error bars represent \pm standard deviation $\left(* P<0.05\right.$, ${ }^{* *} P<0.01$, $\left.* * * P<0.001\right) ; n=$ biological replicates.

Abbreviations: CONPs, cuprous oxide nanoparticles; NOD/SCID, nonobese diabetic/severe combined immunodeficiency; SFE, sphere formation efficiency.

which is not a benefit to the proliferation and movement of cells. Besides, the exciting result was that the reduced expression of CD271 and SOX10 which are considered as the genes maintaining stemness of melanoma stem cells and the downregulated expression of MITF involved in the tumorigenesis, growth, metastasis and drug resistance of melanoma (Figure 4E).

\section{Discussion}

In the previous study, although we had proven that CONPs were safe to mice with great biocompatibility and little systemic toxicity and could well inhibit the growth and metastasis of mice melanoma, whether CONPs could be developed to be novel effective anti-melanoma drug applying in clinic still need more evidence to support. In the current research, we 
A
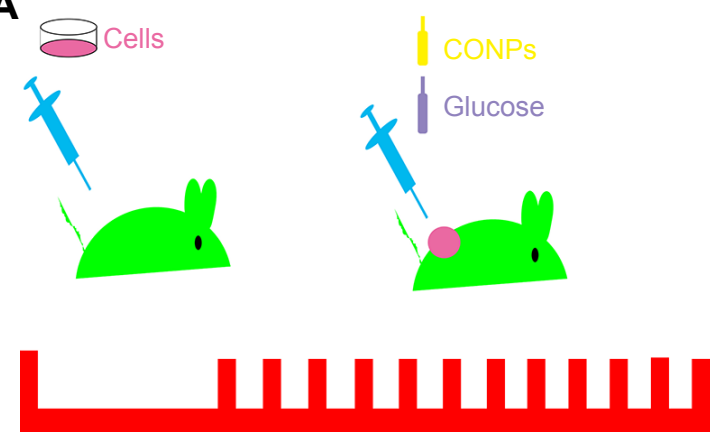

0 day

Cell injection and tumor formation

B
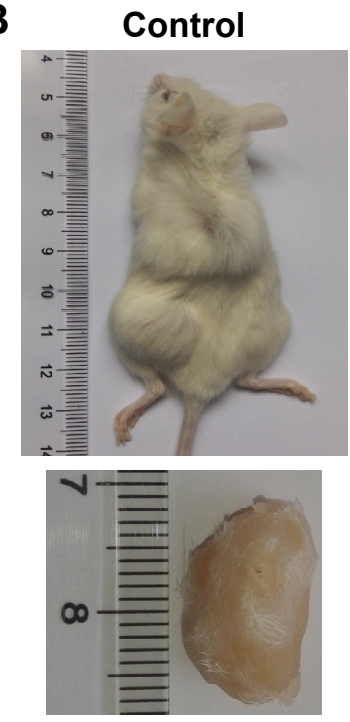

CONP treatment and tumor harvest

22 days

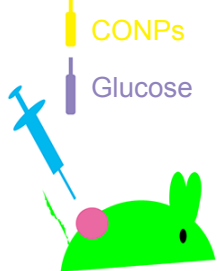

D
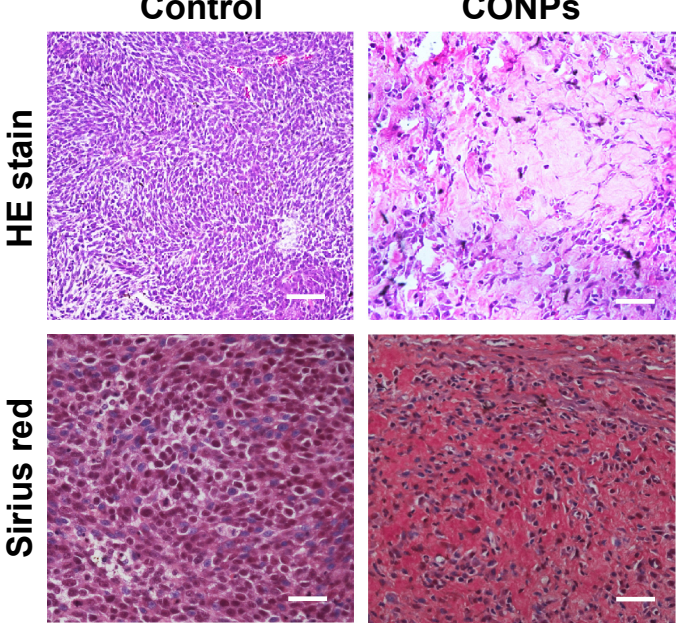

E
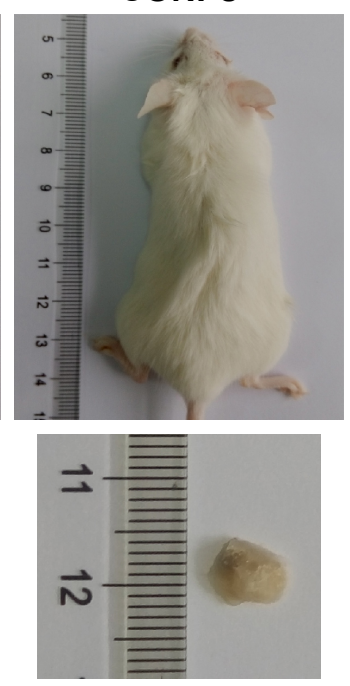

$* *$

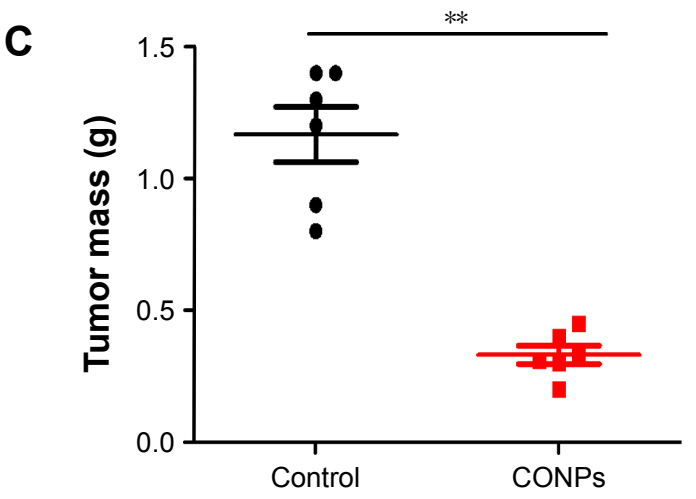

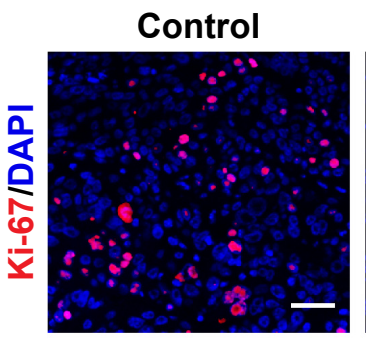
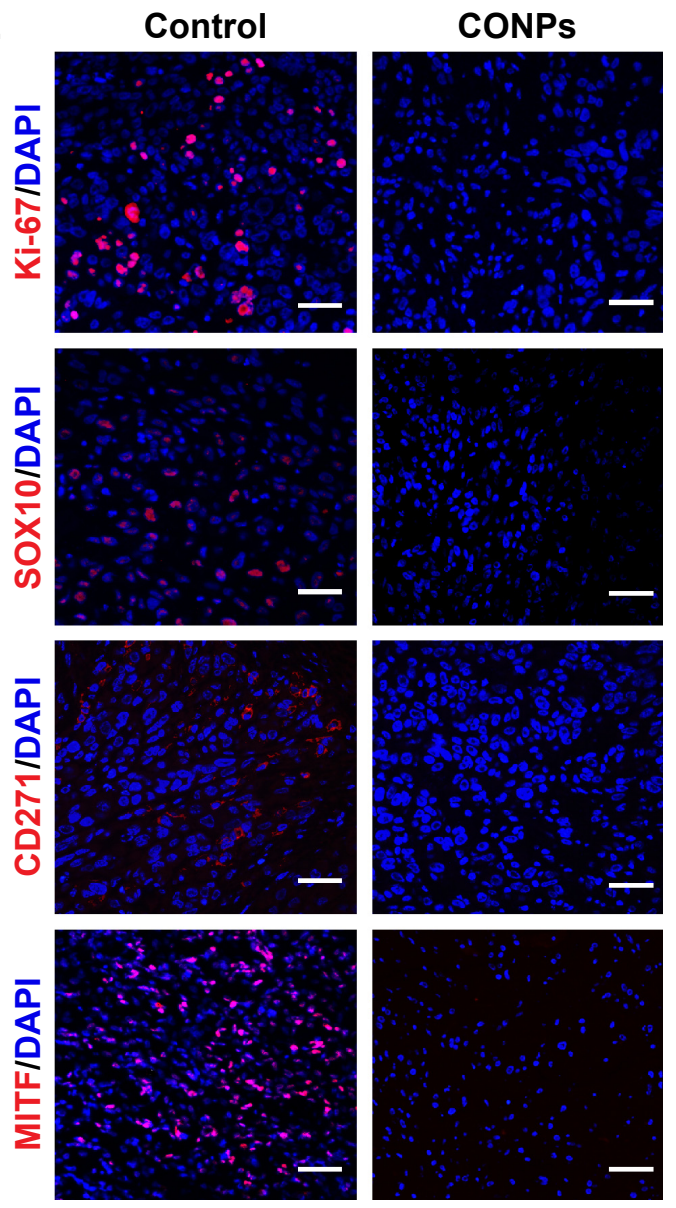

Figure 4 CONPs depressed the growth of melanoma effectively in vivo.

Notes: (A) Scheme of melanoma therapy in vivo with CONPs. All the tumors in CONPs group were treated with CONPs (I6 mg/kg), while control group tumors were treated with $5 \%$ glucose. Intratumoral injection was performed every 2 days and the total volume of injection for each tumor was $0.2 \mathrm{~mL}$ every time. The time span for the treatment was 22 days. (B) Representative images of stripped subcutaneous tumors. The diameters of subcutaneous tumors in the CONPs group were obviously smaller than the diameters in the glucose group. (C) Tumor mass comparison between CONPs and control group. The tumor mass of CONPs group was lower than that of control group after treatment for 22 days. Six mice per group. (D) Representative images of structural damage by H\&E stain and fibrosis by Sirius red stain in CONPs group tumors. Scale bars represent $100 \mu \mathrm{m}$. (E) Representative immunity fluorescence images of paraffin section for tumors of control and CONPs group. Ki-67, SOXI0, CD27I and MITF were stained with red fluorescence and showed the dramatic declination of expression. And the paraffin sections were fixed and stained with DAPI. Scale bars represent $100 \mu \mathrm{m}$. The error bars represent \pm standard deviation $(* * P<0.0 \mathrm{I})$.

Abbreviations: CONPs, cuprous oxide nanoparticles; DAPI, 4',6-diamidino-2-phenylindole; H\&E, hematoxylin and eosin. 
used human melanoma cell lines and mice model to further evaluate anti-melanoma capacity of CONPs. We first proved the effective dose of CONPs to induce the apoptosis of A375 and WM266-4 human melanoma cells was much lower than that to induce B16F10 mouse melanoma cells in vitro. And more importantly, CONPs obviously suppressed the growth of human melanoma tumor, accompanied with tumors structural necrosis and fibrosis remarkably and decreased the expression of genes of CD271, SOX10 and MITF involved in tumor progression, which presented significant antitumor ability in vivo.

As we all know, effectiveness and safety are the crucial properties of clinic drugs. ${ }^{28}$ Low effective dosage means the high value of drugs because of the decreasing potential organ toxicity. To validate the effectiveness of low dosage of CONPs in inhibiting the growth, metastasis and relapse of human melanoma, we tested the alteration of survived cells in melanoma cells after treated with low dosage of CONPs. We chose the $1.75 \mu \mathrm{g} / \mathrm{mL}$ CONPs as the low dosage, which could induce apoptosis of only $17 \%$ of A375 or $12 \%$ of WM266-4 cells after 72-hour treatment. First, survived A375 cells showed G0/G1 arrest that the percentage of cells in the phase of G0/G1 was higher by $25 \%$ than control group. And also the proliferation of survived cells decreased dramatically by $80 \%$ comparing to the control cells shown as the CCK8 assay. Furthermore, we also found the much lower sphere-forming ability of survived cells than control cells, which meant the CONPs reduced the stemness and even tumorigenesis of melanoma proven by the result that the survived cells lose the ability of tumorigenesis in NOD/SCID mice. More importantly, the transwell assay presented that the survived cells no longer have metastasis capacity. The results above all indicated that CONPs exhibited good antimelanoma effect by decreasing the proliferation, metastasis and stemness in lower dosage and inducing apoptosis in the relatively higher dosage treatment.

Our previous studies have elucidated that CONPs could target mitochondrion and induce cell apoptosis through mitochondrion pathway. ${ }^{12,13}$ Our current research tried to find the way by which CONPs entered into cells. To date, there are a few kinds of endocytosis uncovered, via which particles and macromolecules enter into cells, such as clathrin-mediated endocytosis, ${ }^{29}$ macropinocytosis, ${ }^{30}$ and clathrin- and caveola-independent endocytoses. ${ }^{31}$ As inorganic nanoparticles, gold nanospheres (AuNPs) with great antitumor property to breast cancer and other cancers were reported to be taken in by receptor-mediated endocytosis and formed endocytotic vesicles that evolved into lysosomes and autophagosomes through sequential transmission electron microscopy. ${ }^{32-34}$ Similarly, clathrin also mediated the internalization of CONPs. chlorpromazine, ${ }^{35}$ the inhibitor of clathrin-mediated endocytosis, and wortmannin, ${ }^{36}$ an indirect inhibitor of clathrin-mediated endocytosis, could improve cell viability of A375 cells in a dose-dependent manner. In line with the viability improvement, GF-AAS results indicated that chlorpromazine significantly reduced the content of intracellular $\mathrm{Cu}$ in A375 cells exposed to CONPs compared with control cells, which further validated clathrinmediated endocytosis is the major pathway of internalization for CONPs into melanoma cells. However, whether there are special receptors, such as COPT/Ctr family ${ }^{37}$ involved in the endocytosis on the melanoma cell surface need further investigation.

According to $\mathrm{CSC}$ theory, CSCs with drug resistance can escape drug function, which is considered as the leading cause of tumor recurrence and metastasis. In this research, we focused on validating whether CONPs could enter into melanoma stem cells and disrupt them. Recently, researchers have identified CD271 as the marker of melanoma stem cell. ${ }^{21,23}$ First, we confirmed CONPs could induce apoptosis of $\mathrm{CD} 271^{\text {+high }}$ in vitro with the same apoptosis percentage as $\mathrm{CD} 271^{- \text {low }}$ cells induced by CONPs, which suggested that $\mathrm{CD} 271^{\text {+high }}$ cells could not escape from the function of CONPs. In our point of view, CD271 $1^{\text {thigh }}$ cells and CD271-low cells can be regarded as the two subsets of A375 cell lines with different biological characteristics such as in vivo tumorigenicity, self-renewal, drug resistance and tolerance. We proposed that CD271 ${ }^{\text {+high }}$ cells might have an additional mechanism that conferred a strong tolerance to CONPs, which resulted in equivalent level of apoptosis as $\mathrm{CD} 271^{-/ \text {low }}$ cell subset even though CD271 ${ }^{\text {thigh }}$ cells could take in and accumulate more CONPs. Second, quantitative analysis by GFAAS showed that CD271 $1^{\text {thigh }}$ could accumulate much more CONPs, which might lead to the high apoptosis percentage of CD271 $11^{\text {/high }}$ cells. That is to say, CONPs were easier to target melanoma stem-like cells via the higher absorption capability than $\mathrm{CD} 271^{- \text {/low }}$ cells, inducing apoptosis or depressing the proliferation, metastasis and tumorigenesis of melanoma stem cells. Previous reports pointed out that modification on the surface of AuNPs is necessary to help them targeting the special CSC, such as glucose-coated gold nanoparticles. ${ }^{38-40}$ It is the first time we found the inorganic metal particle, CONPs without any other modification, still could be enriched in melanoma stem cells. Thirdly, we elucidated the dramatic decrease of CD271 and SOX10 gene expression in A375 cells after they exposed to the low dosage of CONPs and 
much more significant reduction of SOX10 gene expression in CD271 $1^{\text {thigh }}$ cells than CD271-/low cells treated by CONPs. It is well known that CD271 protein as crucial melanoma stem cell marker drives melanoma tumorigenicity, stemness, heterogeneity and plasticity. ${ }^{21,23,24-27}$ Without CD271 gene expression, tumorigenesis and metastasis of melanoma stem cells would be weakened. Meanwhile, SOX10 (SRY-box transcription factor SOX10) protein is the important marker in malignant tumors, such as melanoma, breast carcinoma and gliomas. ${ }^{39-44}$ It was reported that SOX10 could maintain the multipotency of melanoma stem cells, the tumorigenic and proliferation and metastasis of melanoma cells. ${ }^{19-21}$ In some reports, both CD271 and SOX10 were identified as melanoma stem cell biomarkers to evaluate stemness of melanoma cells. ${ }^{23}$ In this study, the downregulation of CD271 and SOX10 expression resulting from the CONP treatment further supported CONPs have much more superiority in suppressing stemness of melanoma cells and killing melanoma stem cells than some other antitumor drugs.

Moreover, this current research also showed the CONPs could significantly inhibit the expression of MITF (Drosophila transcription factor) in vitro and in vivo, which could be of great significance to treat melanoma effectively..$^{45}$ Recent researches have pointed out the expression of MITF is much higher in melanoma cells, which played the key role in melanoma proliferation and metastasis. ${ }^{46,47}$ Furthermore, repression of MITF expression could make melanoma to recruit myeloid immune cells into the tumor microenvironment which could counteract tumor growth promoting and immunosuppressive functions. ${ }^{48}$ Besides, MITF was related to intrinsic drug resistance and the drug resistance to BRAF inhibitors in melanoma cells, which could further promote cell survival and proliferation. ${ }^{49,50}$ Melanoma cells expressing MITF highly displayed significant drug resistance in BRAF-i and MEK-i treatment. This study presented that low dosage of CONPs could inhibit the expression of MITF in melanoma cells, especially in CD271 ${ }^{\text {+high }}$ cells, implying low dosage of CONPs may inhibit the growth of melanoma in vivo by decreasing drug resistance, contributing to recruiting myeloid immune cells around melanoma tumor through suppressing expression of MITF.

Besides CD271, SOX10 and MITF, CONPs also could suppress the activity of the RAS-RAF-mitogen-activated protein kinase (MAPK) pathway in melanoma, which is hyperactive in melanoma cells resulting from BRAF mutation, a high-frequency mutation in melanoma. ${ }^{51-53} \mathrm{BRAF}$ mutation leads to direct RAF-mediated activating phosphorylation of MEK1 and MEK2. MEK1 and MEK2 in turn activate the ERK1 and ERK2 MAPKs via phosphorylation.
The hyperactivity of MAPK pathway would promote melanoma cell proliferation and survival. At present, many BRAF and MEK inhibitors have been used to cure melanoma in clinical and obviously prolonged patients' survival time. In our study, we have also found low dosage of CONPs not only suppressed CD271, SOX10 and MITF expression, but also disturbed the MAPK pathway, companying with obvious decrease of p-BRAF and p-ERK protein. These results above may provide additional positive evidences to support the effectiveness of CONPs to cure melanoma.

\section{Conclusion}

Above all, our research provided a series of evidences that CONPs could induce apoptosis of melanoma stem cells and inhibited growth of melanoma via reducing expression of genes involved in melanoma progress, which suggest that CONPs have significant potential for melanoma clinical therapy. Furthermore, translational research will be performed in our future research.

\section{Acknowledgments}

We are very grateful to all the members of our labs and Professor Hongli Yan in Laboratory department of Changhai Hospital, SMMU. Work in our laboratories is supported by National Natural Science Foundation of China (No 31471284, 81472771, 31471230, 31501053), Basic Research Program of Shanghai Science and Technology Committee (No 13JC1401402), and Scientific Research Innovation Projects of Shanghai Education Committee (No 14ZZ078).

\section{Disclosure}

The authors report no conflicts of interest in this work.

\section{References}

1. Vogelsang M, Wilson M, Kirchhoff T. Germline determinants of clinical outcome of cutaneous melanoma. Pigment Cell Melanoma Res. 2016; 29(1):15-26.

2. Hai P, Zhou Y, Zhang R, et al. Label-free high-throughput detection and quantification of circulating melanoma tumor cell clusters by lineararray-based photoacoustic tomography. J Biomed Opt. 2017;22(4): 41004.

3. Bennett C. Genetics of melanoma progression: the rise and fall of cell senescence. Pigment Cell Melanoma Res. 2016;29(2):122-140.

4. Leachman S, Cassidy P, Chen C, et al. Methods of melanoma detection. Cancer Treat Res. 2016;167:51-105.

5. Teow J, Chin O, Hanikeri M, Wood BA. Primary dermal melanoma: a West Australian cohort. ANZ J Surg. 2015;85(9):664-667.

6. Thomsen B, Folkvaljon Y, Garmo H, et al. Risk of malignant melanoma in men with prostate cancer: nationwide, population-based cohort study. Int J Cancer. 2016;138(9):2154-2160.

7. Park J, Wrzesinski S, Stern E, et al. Combination delivery of TGFinhibitor and IL-2 by nanoscale liposomal polymeric gels enhances tumour immunotherapy. Nat Mater. 2012;11(10):895-905. 
8. Yao L, Daniels J, Moshnikova A, et al. pHLIP peptide targets nanogold particles to tumors. Proc Natl Acad Sci U S A. 2013;11(10):465-470.

9. Lee S, Kim S, Wu Y, et al. Nanowire substrate-based laser scanning cytometry for quantitation of circulating tumor cells. Nano Lett. 2012;12(6):2697-2704.

10. Su Y, Wei X, Peng F, et al. Gold nanoparticles-decorated silicon nanowires as highly efficient near-infrared hyperthermia agents for cancer cells destruction. Nano Lett. 2012;12(4):1845-1850.

11. Chenchen B, João C, Fei P, et al. Gold nanoprisms as a hybrid in vivo cancer theranostic platform for in situ photoacoustic imaging, angiography, and localized hyperthermia. Nano Res. 2016;9(4):1043-1056.

12. Wang Y, Yang F, Zhang HX, et al. Cuprous oxide nanoparticles inhibit the growth and metastasis of melanoma by targeting mitochondria. Cell Death Dis. 2013;4:e783.

13. Wang Y, Zi X, Su J, et al. Cuprous oxide nanoparticles selectively induce apoptosis of tumor cells. Int J Nanomedicine. 2012;7:2641-2652.

14. Wang T, Shigdar S, Gantier P, et al. Cancer stem cell targeted therapy: progress amid controversies. Oncotarget. 2015;6(42):44191-44206.

15. Burgess R, Huang R. Cancer stem cell biomarker discovery using antibody array technology. Adv Clin Chem. 2016;73:109-125.

16. Jiao X, Rizvanov A, Cristofanilli M, Miftakhova RR, Pestell RG. Breast cancer stem cell isolation. Methods Mol Biol. 2016;1406:121-135.

17. Pang Y, Argyle J. The evolving cancer stem cell paradigm: implications in veterinary oncology. Vet J. 2015;205(2):154-160.

18. Islam F, Qiao B, Smith R, Gopalan V, Lam AK. Cancer stem cell: fundamental experimental pathological concepts and updates. Exp Mol Pathol. 2015;98(2):184-191.

19. Wilson J, Saab K, Ma J, et al. ABCB5 maintains melanoma-initiating cells through a proinflammatory cytokine signaling circuit. Cancer Res. 2014;74(15):4196-4207.

20. Vásquez I, Meraz A, Villanueva G, et al. ATP-binding cassette transporter $\mathrm{ABCB} 5$ gene is expressed with variability in malignant melanoma. Actas Dermosifiliogr. 2010;101(4):341-348.

21. Boiko A, Razorenova O, Swetter SM, et al. Human melanoma-initiating cells express neural crest nerve growth factor receptor CD271. Nature. 2010;466(7302):133-137.

22. Luo Y, Nguyen N, Fujita M. Isolation of human melanoma stem cells using ALDH as a marker. Curr Protoc Stem Cell Biol. 2013;26:Unit 3.8.

23. Civenni G, Walter A, Kobert N, et al. Human CD271-positive melanoma stem cells associated with metastasis establish tumor heterogeneity and long-term growth. Cancer Res. 2011;71(8):3098-3109.

24. Furuta J, Inozume T, Harada K, Shimada S. CD271 on melanoma cell is an IFN- $\gamma$-inducible immunosuppressive factor that mediates downregulation of melanoma antigens. J Invest Dermatol. 2014;134(5): 1369-1377.

25. Sigal AC, Keenan M, Lazova R. P75 nerve growth factor receptor as a useful marker to distinguish spindle cell melanoma from other spindle cell neoplasms of sun-damaged skin. Am J Dermatopathol. 2012;34(2):145-150.

26. Guo R, Fierro A, Goddard L, et al. Increased expression of melanoma stem cell marker CD271 in metastatic melanoma to the brain. Int J Clin Exp Pathol. 2014;7(12):8947-8951.

27. Lehraiki A, Cerezo M, Rouaud F, et al. Increased CD271 expression by the NF-kB pathway promotes melanoma cell survival and drives acquired resistance to BRAF inhibitor vemurafenib. Cell Discov. 2015;1:15030.

28. Gandhi TK, Seger DL, Bates DW, et al. Identifying drug safety issues: from research to practice. Int J Qual Health Care. 2000;12(1):69-76.

29. Lu R, Drubin DG, Sun Y. Clathrin-mediated endocytosis in budding yeast at a glance. $J$ Cell Sci. 2016;129(8):1531-1536.

30. Mercer J, Helenius A. Virus entry by macropinocytosis. Nat Cell Biol. 2009;11(5):510-520.

31. Kirkham M, Parton RG. Clathrin-independent endocytosis: new insights into caveolae and non-caveolar lipid raft carriers. Biochim Biophys Acta. 2005;1745(3):273-286.
32. Lee J, Chatterjee D, Lee M, Krishnan S. Gold nanoparticles in breast cancer treatment: promise and potential pitfalls. Cancer Lett. 2014; 347(1):46-53.

33. Dreaden EC, Austin LA, Mackey MA, El-Sayed MA. Size matters: gold nanoparticles in targeted cancer drug delivery. Ther Deliv. 2012;3(4):457-478.

34. Zhao J, Lee P, Wallace MJ, Melancon MP. Gold nanoparticles in cancer therapy: efficacy, biodistribution, and toxicity. Curr Pharm Des. 2015;21(29):4240-4251.

35. Daniel JA, Chau N, Abdel MK, et al. Phenothiazine-derived antipsychotic drugs inhibit dynamin and clathrin-mediated endocytosis. Traffic. 2015;16(6):635-654.

36. Liu Y, Shreder KR, Gai W, Corral S, Ferris DK, Rosenblum JS. Wortmannin, a widely used phosphoinositide 3-kinase inhibitor, also potently inhibits mammalian polo-like kinase. Chem Biol. 2005;12(1): 99-107.

37. Yuan M, Li X, Xiao J, Wang S. Molecular and functional analyses of COPT/Ctr-type copper transporter-like gene family in rice. BMC Plant Biol. 2011;11:69.

38. Hu C, Niestroj M, Yuan D, Chang S, Chen J. Treating cancer stem cells and cancer metastasis using glucose-coated gold nanoparticles. Int $J$ Nanomedicine. 2015;10:2065-2077.

39. Xu Y, Wang J, Li X, et al. Selective inhibition of breast cancer stem cells by gold nanorods mediated plasmonic hyperthermia. Biomaterials. 2014;35(16):4667-4677.

40. Sun TM, Wang YC, Wang F, et al. Cancer stem cell therapy using doxorubicin conjugated to gold nanoparticles via hydrazone bonds. Biomaterials. 2014;35(2):836-845.

41. Miettinen M, Mccue P, Sarlomo M, et al. Sox10 - a marker for not only schwannian and melanocytic neoplasms but also myoepithelial cell tumors of soft tissue: a systematic analysis of 5134 tumors. Am J Surg Pathol. 2015;39(6):826-835.

42. Willis B, Johnson G, Wang J, Cohen C. SOX10: a useful marker for identifying metastatic melanoma in sentinel lymph nodes. Appl Immunohistochem. 2015;23(2):109-112.

43. Shakhova O, Zingg D, Schaefer SM, et al. Sox 10 promotes the formation and maintenance of giant congenital naevi and melanoma. Nat Cell Biol. 2012;14(8):882-890.

44. Jennings C, Kim J. Identification of nodal metastases in melanoma usingsox-10. Am J Dermatopathol. 2011;33(5):474-482.

45. Hartman M, Czyz M. MITF in melanoma: mechanisms behind its expression and activity. Cell Mol Life Sci. 2015;72(2):1249-1260.

46. Roider E, Fisher D. The impact of MITF on melanoma development: news from bench and bedside. J Invest Dermatol. 2014;134(1):16-17.

47. Ploper D, Taelman V, Robert L, et al. MITF drives endolysosomal biogenesis and potentiates Wnt signaling in melanoma cells. Proc Natl Acad Sci U S A. 2015;112(5):E420-E429.

48. Riesenberg S, Groetchen A, Siddaway R, et al. MITF and c-Jun antagonism interconnects melanoma dedifferentiation with pro-inflammatory cytokine responsiveness and myeloid cell recruitment. Nat Commun. 2015;6:8755.

49. Pathria G, Garg B, Borgdorff V, et al. Overcoming MITF-conferred drug resistance through dual AURKA/MAPK targeting in human melanoma cells. Cell Death Dis. 2016;7:e2135.

50. Smith MP, Brunton H, Rowling EJ, et al. Inhibiting drivers of nonmutational drug tolerance is a salvage strategy for targeted melanoma therapy. Cancer Cell. 2016;29(3):270-284.

51. Cargnello M, Roux PP. Activation and function of the MAPKs and their substrates, the MAPK-activated protein kinases. Microbiol Mol Biol Rev. 2011;75(1):50-83.

52. Dhomen N, Reis JS, Rocha S, et al. Oncogenic Braf induces melanocyte senescence and melanoma in mice. Cancer Cell. 2009;15(4): 294-303.

53. Xiao S, Yang M. Discovery of a novel target for cancer: PRR14. Cell Death Dis. 2016;7(12):e2502. 
International Journal of Nanomedicine

Dovepress

\section{Publish your work in this journal}

The International Journal of Nanomedicine is an international, peerreviewed journal focusing on the application of nanotechnology in diagnostics, therapeutics, and drug delivery systems throughou the biomedical field. This journal is indexed on PubMed Central, MedLine, CAS, SciSearch ${ }^{\circledR}$, Current Contents ${ }^{\circledR} /$ Clinical Medicine,
Journal Citation Reports/Science Edition, EMBase, Scopus and the Elsevier Bibliographic databases. The manuscript management system is completely online and includes a very quick and fair peer-review system, which is all easy to use. Visit http://www.dovepress.com/ testimonials.php to read real quotes from published authors.

Submit your manuscript here: http://www.dovepress.com/international-journal-of-nanomedicine-journal 